J ohn C. Robertson is an assistant professor of economics at the Australian National University and a visiting scholar at the Federal Reserve Bank of Atlanta. Daniel L. Thornton is an assistant vice president and economist at the Federal Reserve Bank of St. Louis. J onathan Ahlbrecht provided research assistance.

\title{
Using Federal Funds Futures Rates to Predict Federal Reserve Actions
}

\section{John C. Robertson and Daniel L. Thornton}

r he Federal Reserve implements monetary policy by making discrete adjustments to its target for the federal funds rate. Such adjustments are believed to have significant implications for other short-term interest rates, so considerable resources are expended on forecasting the timing and magnitude of the Fed's next move. Many analysts, both inside and outside of the Federal Reserve System, look to the federal funds futures market for an indication of whether the market anticipates a change in Fed policy. Because futures market participants make commitments that are contingent on what they believe the federal funds rate will be, they necessarily look to factors they believe will influence its course. The Fed targets the funds rate, and the overnight federal funds rate stays close, on average, to the F ed's target. Hence, the federal funds futures rate naturally embodies the market's expectation of what the Fed will do.

Because of how the federal funds futures market is structured, using the federal funds futures rate as a gauge of the market's expectation for Fed action is trickier than it may at first appear. The purpose of this article is to point out the issues that arise in using the federal funds futures rate to forecast a change in monetary policy. In addition, we present some evidence on the relationships among the federal funds rate, the federal funds futures rate, and the federal funds target rate, and the usefulness of the federal funds futures rate as a predictor of whether the Fed will change its target.

\section{THE FEDERAL FUNDS FUTURES MARKET}

The Chicago Board of Trade (CBOT) began offering federal funds futures contracts in October 1988 (CBOT, 1992). Unlike T-bill futures contracts, where the contract is for the T-bill rate on a specific day, the federal funds futures contract is for the simple average of the daily effective federal funds rate during the month of the contract. The effective federal funds rate is a weighted average of all federal funds transactions for a group of federal funds brokers who report to the Federal Reserve Bank of New York each day. The CBOT offers contracts ranging from the current month to 24 months out. Contracts have a nominal value of $\$ 5$ million, and their settlement price is equal to 100 minus the average of the effective federal funds rate for the month of the contract. Hence, a market price of 94.3 for a one-month contract on October 15 means that the current futures rate for November is 5.7 percent $(100-94.3)$.

The Futures Rate as a Predictor of the Average Federal Funds Rate

The futures rate is an obvious measure of the market's prediction for the monthly average effective federal funds rate, after allowing for the possibility of a non-zero risk premium. That is,

$$
F F F_{t, i}=E_{t} \overline{F F}_{t+i}+\alpha_{i},
$$

where $E_{t}$ denotes the expectation conditional on all the available information up to $\mathrm{t} ; \mathrm{FFF}_{\mathrm{t}, \mathrm{i}}$ is the $\mathrm{i}$-month ahead futures rate; $\overline{F F}_{t+i}$ is the average of the daily effective federal funds rate for each day of the month; and $\alpha_{i}$ is a bias term that varies with the forecast horizon. 


\section{Figure 1}

\section{Spread between the Fed Funds Futures Rates and the Average Fed Funds Rate $F F F_{t, i}-\overline{F F}_{t+i}$}

Percent

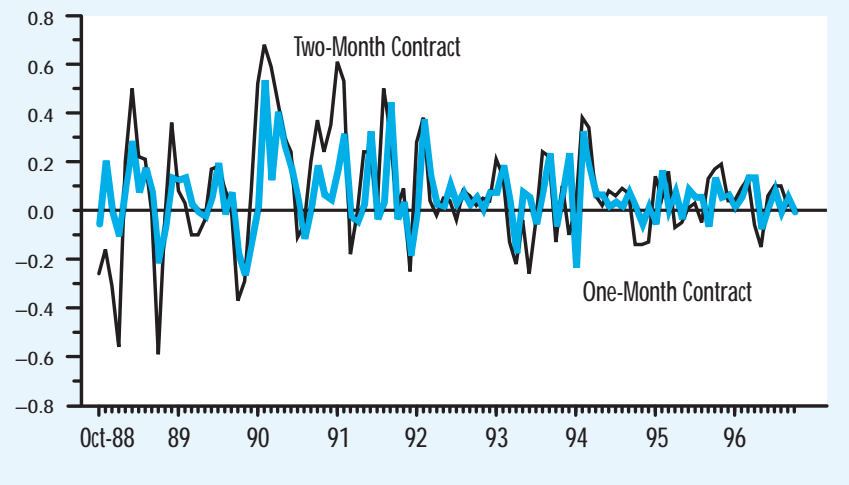

Figure 1 presents the implied forecast error, $F F F_{t, i}-\overline{F F}_{t+i}$, for one- and two-month contracts, where the futures rate is that of the last day of the month for the period October 1988 through August 1997. Because the data are measured on a monthly frequency, the forecast errors follow MA(i-1) processes. Also note that the variability of both series has been somewhat lower since 1995. ${ }^{1}$

The serial correlation-adjusted estimates suggest a significant positive bias in the federal funds futures rate forecast at both horizons, with the bias increasing as the forecast horizon lengthens. These estimates are consistent with the presence of a hedging premium in the futures market. For the one-month forecast, the bias estimate is 3.7 basis points, with a standard error of 1.3 basis points. For the two-month forecast, the bias estimate is 7.5 basis points, with a standard error of 3.0 basis points.

One possible explanation for the hedging premium is that large banks, which regularly finance a significant amount of their loan portfolios in the spot market for federal funds, also participate in the federal funds futures market. Such institutions may use the futures market to hedge against increases in the spot funds rate. If institutions that are hedging against a potential increase in the spot rate are dominant, there could be a premium built into the futures rates.

\section{The Futures Rate as a Predictor of Fed Actions}

Because the funds rate tends to stay reasonably close to the funds rate target on average, it is not uncommon for analysts to look to the federal funds futures market for an indication of whether a change in Fed policy is expected. However, two interrelated issues make it extremely difficult to infer the market's expectation for Fed action from the behavior of the federal funds futures rate, even after adjusting for the underlying bias. First, the futures rate is a forecast of the average federal funds rate and not a forecast of the average federal funds rate target. Second, the effect of a target change on the average federal funds rate depends on the timing and magnitude of the target change. We now consider the effect of each of these issues on the interpretation of the federal funds futures rate.

\section{The Futures Rate and the Funds Rate Target}

The fact that the futures rate is not strictly a forecast of the funds rate target leads to an obvious identification problem. To illustrate the problem, we express the market's forecast of the average funds rate as the sum of the forecast for the average funds rate target and the expected deviation of the average funds rate from the average target. Substituting for the expected average funds rate from Equation 1 then gives

$$
\begin{aligned}
& F F F_{t, i}-\alpha_{i}=E_{t} \overline{F F T}_{t+i} \\
& +E_{t}\left(\overline{F F}_{t+i}-\overline{F F T}_{t+i}\right),
\end{aligned}
$$

where $\overline{F F T}_{t+i}$ is the average federal funds target rate for month $\mathrm{t}+\mathrm{i}$. The bias-adjusted futures rate and the market's forecast for the average target rate will differ when the market expects the average funds rate to deviate from the average target. Hence, the expected target component of the forecast cannot be deduced from the federal funds futures rate without making additional assumptions. 
One common assumption, sufficient to identify the market's expectation for the average funds rate target, is that the market al ways forecasts the average funds rate to coincide with the average target rate, i.e., $E_{t}\left(\overline{F F}_{t+i}-\overline{F F T}_{t+i}\right)=0$. If this were true, the bias-adjusted futures rate would be the market's forecast for the average funds rate target. Since the futures rate rarely coincides with the current target, one would conclude that the market is almost always forecasting a change in the target. ${ }^{2}$

We think it is unlikely that market participants al ways expect the average funds rate to equal the average of the funds rate target. The expectation for the difference between these rates is likely to be based on estimates of general market conditions, the reserves positions of banks, and whether and by how much the funds rate is permitted to deviate from the funds rate target. For one thing, the average funds rate has tended to be above the average funds rate target by about three basis points over the sample period. That is, the average funds rate is a biased estimate of the average funds rate target. In addition, when the average funds rate is above or below the funds rate target, it tends to remain so for a few months, that is, there is mild positive serial correlation. Market participants likely utilize such information in developing their forecasts.

\section{A Partial Identifying Assumption}

N umerous other assumptions could be made to recover the underlying market expectations for the average of the federal funds rate target. However, estimates of the market's expectation will depend on the particular identifying assumption used. Here we consider an example of what might be called a partial identifying assumption. It is a partial identifying assumption because it is sufficient only to identify some of the occasions when the market is anticipating a change in the funds rate target. It is insufficient for determining the magnitude of the expected target change. Moreover, it is incapable of determining all of the occasions when the market is expecting no change in the target. Specifically, suppose we know that
$E_{t}\left(\overline{F F}_{t+i}-\overline{F F T}_{t+i}\right)$ al ways falls within a certain interval. If the bias-adjusted $\mathrm{i}$-month spread between the futures rate and the current target rate is outside this interval, we can conclude that the market expects a target change. While we can be fairly certain that the market is expecting a change in the target, we will not know the magnitude of the change. If, on the other hand, the bias-adjusted spread is inside this interval, we cannot conclude that the market is not expecting a target change. It might be that the market is expecting a target change that will have a relatively small effect on the bias-adjusted futures rate.

To illustrate the implications of this assumption, subtract the current level of the funds rate target, $F F T_{t}$, from both sides of Equation 2 to give:

$$
\begin{aligned}
& F F F_{t, i}-F F T_{t}-\alpha_{i} \\
& =E_{t}\left(\overline{F F}_{t+i}-\overline{F F T}_{t+i}\right)+E_{t}{\overline{F F T_{t+i}}}_{t}-F F T_{t} .
\end{aligned}
$$

Assume for the moment that the market's forecast of how much the average funds rate deviates from the average target is known to always range between -20 and +20 basis points. If the market expects no change in the target, the bias-adjusted spread is simply

$$
F F F_{t, i}-F F T_{t}-\alpha_{i}=E_{t}\left(\overline{F F}_{t+i}-\overline{F F T}_{t+i}\right),
$$

and this spread will also vary between -20 and +20 basis points. If the bias-adjusted one-month spread is outside this interval, it must be that the market expects a change in the target. If the spread is inside the interval, it may or may not be the case that the market expects a change in the target.

\section{The Expected Timing and Magnitude of Target Changes}

Over the period from October 1988 to August 1997, there were 38 months when the Fed changed its target for the federal funds rate. There were 25 decreases in the target and 13 increases. On all but four occasions, the target change was 25 , 50 , or 75 basis points, with the majority of the changes being 25 basis points.

\footnotetext{
${ }^{2}$ Implicitly one is assuming that the market is always assigning some probability, $P$, to a nonzero change in the target. According to this view, $E_{t} F F T_{t+i}-F F T_{t}$, is equal to $P$ times the expectation of a non-zero target change. However, this interpretation does not allow us to identify $P$. For example, suppose that the bias-adjusted spread between the futures rate and the current target rate is 10 basis points. This spread is consistent with a 20 percent probability of an expected 50 basis-point increase, a 40 percent probability of an expected 25 basis-point increase, or an infinite number of alternatives. When the issue of the timing of the change is considered, the identification problem becomes even more severe.
} 


\section{Figure 2}

\section{Spread between the Average Fed Funds Rate and the Average Fed Funds Rate Target}

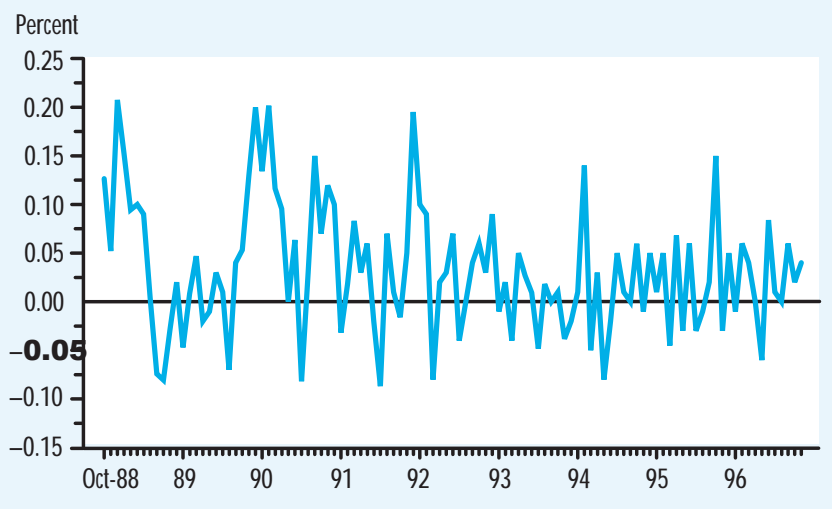

Before August 1989, it was not uncommon for the Fed to make two or more adjustments to its federal funds rate target in a month.

The Fed's adjustments to its funds rate target affect the level of the corresponding federal funds rate. However, the federal funds futures market forecasts the monthly average of the funds rate, not the funds rate on any particular day. Consequently, an expected target change's effect on the futures rate depends on when and by how much the target is expected to change. This problem interacts with the previously noted identification problem. To see how, assume that at the end of the month the target rate is 5 percent, the bias-adjusted federal funds futures rate is 5.13 percent, and the average funds rate is expected to lie within \pm 20 basis points of the average funds rate target. We might conclude that the market is not anticipating a change in the funds rate target. On the other hand, it might be that the market expects the average funds rate to equal the average funds rate target next month. In this case, the 13-basis-point spread is consistent with an expected rise in the target of 25 basis points about mid-month, an increase of 50 basis points about threequarters of the way through the month, or even a 75-basis-point rise very late in the month.
The predicament is perhaps most severe when the market is anticipating a policy action late in the upcoming month. For example, assume that futures market participants are anticipating a 50-basispoint change in the funds rate target, from 5 percent to 5.5 percent, on the twentyseventh day of the next month, and suppose that the bias-adjusted one-month futures rate is 5.05 percent. Such a small spread value could easily be mistaken to indicate that no change in the target is expected. Of course, if the market is predicting no action in the subsequent month, the two-month futures rate should be about 50 basis points higher than the current target rate. Hence, a comparison of the one-month and two-month contracts would help determine whether the market is anticipating a Fed action next month. Even then, it would be easy to infer that the market is anticipating a target change two months from now, rather than next month.

\section{PREDICTING A TARGET CHANGE}

We have argued that it is extremely difficult to extract the market's expectation for the Fed's funds rate target from the behavior of the federal funds futures rate. However, this difficulty need not prevent us from exploring the usefulness of the futures rate for forecasting changes in the Fed's target. To illustrate, reconsider the partial identifying assumption described previously. To make this procedure operational, we assume that the bounds of $E_{t}\left(\overline{F F}_{t+i}-\overline{F F T}_{t+i}\right)$ in any period are the largest and smallest values of $\left(\overline{F F}_{t}-\overline{F F T}_{t}\right)$ over the whole sample period. This assumption is arbitrary, but it is perhaps not too unrealistic.

As can be seen in Figure 2, the difference between the average funds rate and the average target is often large, ranging between about -9 and +21 basis points over the sample period. Also, there is no tendency for the two series to drift apart for too long over time; consequently, the serial correlation of the difference is only 


\section{Figure 3}

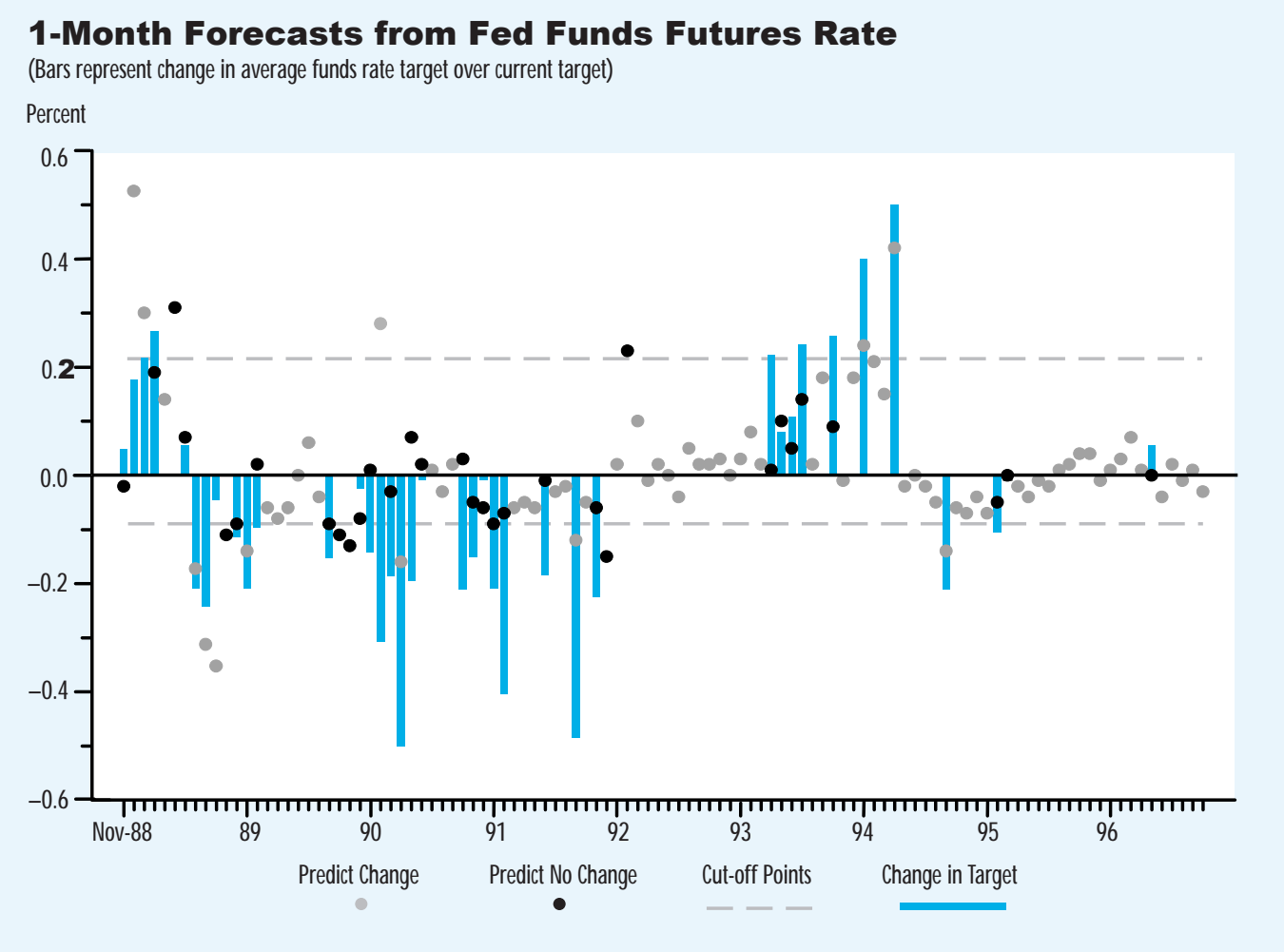

\section{Table 1}

\section{Contingency Table for One-Month Spread}

\begin{tabular}{ccccc}
\hline Predict Change & $12^{*}$ & Actual Change & Actual No Change & Predicted Total \\
\hline Predict No Change & 26 & 6 & 18 \\
Actual Total & 38 & 62 & 88 \\
\hline
\end{tabular}

* One of the predicted changes was in the wrong direction.

mildly positive. That the range is asymmetric about zero stems in part from the fact that the funds rate has tended to be above the target level (see shaded insert for an analysis of the sources of this bias). Our estimate of the forecast bias in the one-month futures rate is about four basis points. Given our assumptions, when the bias-adjusted spread between the one-month futures rate and the current target rate is outside the cut-off points, the futures market is forecasting a target change next month. A spread that is inside the interval may or may not indicate an expected target change. However, for the purpose of this discussion we treat such outcomes as forecasts of no target change. This potential misclassification of expectations could be a major source of forecast error.

Figure 3 presents the one-month bias-adjusted spread for the period November 1988-August 1997. The sample mean is 1.0 basis point, and the standard deviation is 12.3 basis points. The horizontal lines give the cutoff points, and the vertical bars give the difference between the current target and the average target in the following month. Not surprisingly, the difference between the endof-month target rate and the average target rate for the following month is almost always less than the actual target change. 


\section{Table 2}

\section{Contingency Table for Two-Month Spread When Forecast "No Change" from One-Month Spread}

\begin{tabular}{cccc} 
& $\begin{array}{c}\text { Predicted No } \\
\text { Change/ Actual } \\
\text { Change }\end{array}$ & $\begin{array}{c}\text { Predicted No } \\
\text { Change/ Actual No } \\
\text { Change }\end{array}$ & Predicted Total \\
\hline Predict Change & 14 & 16 & 30 \\
\hline Predict No Change & 12 & 46 & 58 \\
\hline Total & 26 & 62 & 88 \\
\hline
\end{tabular}

For example, there has been a 25basis-point change on 24 occasions since October 1988- 19 decreases and 5 increases. A total of five of the decreases and two of the increases resulted in less than a 13-basis-point change in the average target level. The forecast results are summarized in a contingency table, Table 1.

Going down the column of Table 1 headed "Actual Change," we see that our empirical rule correctly predicts a change in the target on only 12 of the 38 occasions that the target was changed and predicts no change on the remaining 26 months. Thus, the accuracy of this forecast is 32 percent (12/38), and on one occasion (December 1990), the prediction was that the Fed would raise the target when, in fact, it was reduced. Going down the column headed "Actual No Change," we see that the rule correctly predicts no change in 62 of the 68 months when the Fed did not change its target. Hence, the accuracy of the no-change forecast is 91 percent $(62 / 68)$. The overall accuracy is 70 percent (74/106).

While forecast accuracy is important, so is forecast reliability. The rule only predicts that the target will change on a total of 18 occasions. The proportion of these forecasts that is actually correctthe hit rate- is 67 percent $(12 / 18)$. The forecasts of no change are slightly more reliable. The rule predicts no target change 88 times, so the hit rate is 70 percent $(62 / 88) .^{3}$
Notice that the cutoff points are asymmetric about zero. The basis-adjusted spread was less than -9 basis points on four of the six occasions that the rule incorrectly forecast a change, while on the remaining two occasions it was above 22 basis points. Given our assumptions, these are forecast errors. Conversely, the one-month futures rate was below the current target rate on 13 of the 26 times that the rule incorrectly forecast no target change, above it 11 times, and equal to it on two occasions. Of course, we cannot infer that these were necessarily forecasting mistakes by the market, since the rule cannot distinguish among small spread values.

One reason for the rule's low accuracy in predicting target changes is that the futures market predicts the average level of the funds rate. When the rule indicates that the market is not predicting a target change, it may actually be predicting a target change late in the month. Hence, when the one-month rate predicts no change and a change occurs, it is useful to look to the two-month federal funds futures rate to see if the market may have been anticipating a target change late in the month.

Table 2 summarizes the results for the two-month spread for the 88 occasions in Table 1 when the one-month contract predicted no change in the target. The bias is set at eight basis points, and the implied interval is still -9 to 21 basis points. As we can see, of the 26 occasions when the rule predicts no change next month but a change occurs, a target change is predicted at the two-month horizon on 14 occasions. Of the 62 months when the rule correctly predicts no change the next month, the twomonth spread predicts a change for the following month on 16 occasions.

Table 3 presents a revised contingency table for the one-month forecast based on the spreads for the one-month and two-month federal funds futures rates. Incorporating the two-month rate spread has little effect on the overall forecast accuracy: It declines slightly to 68 percent 


\section{WHY IS THE FUNDS RATE A BIASED ESTIMATOR OF THE FUNDS RATE TARGET?}

The spread between the monthly average funds rate and the average funds rate target indicates a bias of 3.1 basis points, with a t-ratio of 3.7..$^{\dagger}$ That is, the monthly average funds rate has tended to average slightly higher than the monthly average for the funds rate target. The standard deviation of the series is 6.2 basis points, and the variability appears to be smaller in the latter part of the sample.

One potential source of this bias is the effect of settlement Wednesdays. The funds rate deviates substantially from the targeted level on the final day of the reserve maintenance period, called settlement Wednesday. It is unusually high if reserves are scarce or unusually low if reserves are abundant. If, on average, reserves were a little scarce on reserve settlement days, the monthly funds rate could average a few basis points higher than the target.

It is also possible that the behavior of this series has changed over time, partly in response to the Fed's disclosure policy. Evidence (Thornton, 1996) indicates that, prior to the Fed's policy of immediate disclosure, the market took a few days to figure out that the Fed had changed its funds rate target. If so, the funds rate would trade above the target when the Fed reduced the target and below it when the target was raised. During the period prior to immediate disclosure, the Fed changed its funds rate target 27 times. Of these, 22 were decreases, and only 5 were increases. Hence, it would not be surprising to see a positive bias in the funds rate over the funds rate target for this period, but the bias should disappear with immediate disclosure.

Formerly, the Federal Open Market Committee (FOMC) announced its policy decisions about six weeks after the previous meeting. At its February 1994 meeting, the FOMC broke this long-standing tradition and announced the decision as soon as it was made. While the FOMC made no commitment to continue the practice, the next five changes (all increases) were announced immediately. The new policy was formalized at the February 1995 meeting.

Evidence of the importance of the effect of settlement Wednesdays and immediate disclosure is obtained by re-estimating the average spread. We investigate the possibility of a settlement Wednesday effect by replacing the simple monthly average of the effective federal funds rate with a monthly average rate that excludes settlement Wednesdays. We test the possibility that immediate disclosure could account for the non-zero mean by estimating the average over the period from February1994 to August 1997.

The results, summarized in the table above, suggest that both of these factors have played a role. Using data adjusted for settlement Wednesdays, we find that the average spread of the funds rate over the funds rate target for the period from N ovember 1988 to August 1997 was only 1.43 basis points; however, the mean is statistically significant at the 10 percent level. Hence, while the settlement Wednesday effect plays a role in the bias of the funds rate, it does not appear to account for it all.

The estimated mean over the period since immediate disclosure is 1.53 basis points, and the null hypothesis that the mean is zero is rejected at the 5 percent level of significance. When settlement Wednesdays are excluded, the estimated mean drops to less than one basis point and is not statistically significant.

${ }^{\dagger}$ AR(1) process was used. 


\section{Table 3}

\section{Revised Contingency Table For the One- Month Horizon Based on the One- and Two-Month Federal Funds Futures Rates}

\begin{tabular}{c|c|c|c|}
\hline & Actual Change & Actual No Change & Predicted Total \\
\hline Predict Change & $26^{*}$ & 22 & 48 \\
\hline Predict No Change & 12 & 46 & 58 \\
\hline Actual Total & 38 & 68 & 106 \\
\hline
\end{tabular}

* One of the predicted changes was in the wrong direction.

(72/106). However, using both the onemonth and two-month spreads makes the target change forecasts substantially more accurate, 68 percent (26/38), but at a cost of reduced reliability, 54 percent (26/48). The accuracy for no-change forecasts declines to 68 percent $(46 / 68)$, while the hit rate increases to 79 percent (46/58). Hence, a more accurate forecast of a target change is also associated with lower accuracy in forecasting no change.

\section{CONCLUSIONS}

The federal funds futures market naturally embodies the market's expectation of future Fed policy. However, the federal funds futures rate is a forecast of the average monthly level of the funds rate. The potential for bias and the fact that the federal funds futures rate forecasts the funds rate and not the funds rate target means that using it for forecasting Fed action is considerably more difficult than it might at first appear.

This article discusses the consequences of these difficulties for interpreting the spread of the one-month-

${ }^{4}$ For instance, the time series properties of the funds rate target itself can be utilized to form a forecasting rule. The fed funds futures rate may be a useful predictor in this context (see Robertson and Thomton, 1997). ahead futures rate over the current target rate. In particular, we show that there is a fundamental identification problem that can be overcome only by making some additional and somewhat arbitrary assumptions. Using a particular partial identifying assumption, we investigate the predictive accuracy of the federal funds futures rate over the period October 1988-August 1997. Our empirical forecasting rule correctly predicts a target change in the following month only about one-third of the time. The rule is much better at forecasting no change in the target and has an overall forecast reliability of around 70 percent. When the two-month federal funds futures rate is incorporated into the analysis, the accuracy of the rule in forecasting target changes one month in advance is substantially improved. There is some deterioration in forecast reliability, however.

Because our criterion identifies only expected changes in the target that have a sufficiently large impact on the futures rate, there is considerable uncertainty about the interpretation of small deviations of the futures rate from the current target. Consequently, the forecast errors are not necessarily forecasting mistakes by the market.

Because our forecasts are based on the federal funds futures rate for the last day of the month and the Fed changes its target at various times during the month, the forecast horizon is not held constant. It is likely that the forecast accuracy will vary with the forecast horizon. This fact is of particular interest now because the FOMC has followed the practice of changing its funds rate target at regularly scheduled meetings since it adopted the policy of immediate disclosure. Also, because meeting dates are known in advance, the market should not be expecting a target change in months when there is no meeting. Although they do not account for the inherent randomness of the federal funds futures rate nor its bias, Pakko and Wheelock (1996) find that the futures rate predictions improve a few days prior to FOMC meetings. It would be interesting to see whether there is an optimal horizon for predicting Fed target changes and how well the federal funds futures rate performs relative to other predictors of Fed activity. These subjects are left for other research. ${ }^{4}$ 


\section{REFERENCES}

Chicago Board of Trade. 30-Day Interest Rate Futures:

For Short-Term Interest Rate Management, 1992.

Krueger, Joel T., and Kenneth N. Kuttner. "The Fed Funds Futures Rate as a Predictor of Federal Reserve Policy," Joumal of Futures Markets ( December 1996), pp. 865-79.

Pakko, Michael R., and David C. Wheelock. "Monetary Policy and Financial Market Expectations: What Did They Know and When Did They Know It.?" this Review (July/ August 1996), pp. 19-32.

Robertson, John C., and Daniel L. Thornton. "Alternative Approaches to Forecasting Fed Action," Manuscript, Federal Reserve Bank of St. Louis, 1997

Thornton, Daniel L. "The Other Change in Fed Procedure," Federal Reserve Bank of St. Louis, Monetary Trends (July 1997).

"Does the Fed's New Policy of Immediate Disclosure Affect the Market?," this Review (November/ December 1996), pp. 77-88. 